\title{
Erratum: Particle-in-cell simulation of x-ray wakefield acceleration and betatron radiation in nanotubes [Phys. Rev. Accel. Beams 19, 101004 (2016)]
}

\author{
Xiaomei Zhang, Toshiki Tajima, Deano Farinella, Youngmin Shin, Gerard Mourou, \\ Jonathan Wheeler, Peter Taborek, Pisin Chen, Franklin Dollar, and Baifei Shen \\ (Received 28 October 2016; published 21 November 2016)
}

DOI: $10.1103 /$ PhysRevAccelBeams.19.119902

In Table I on page 3 and Table II on page 5 in the paper, the unit of plasma density $n_{\text {tube }}$ should be $/ \mathrm{cm}^{3}$ instead of $\mathrm{W} / \mathrm{cm}^{3}$, and the tube radius $\sigma_{\text {tube }}$ should be $2.5 \mathrm{~nm}(\mu \mathrm{m})$ instead of $2.5 \mathrm{~nm}(\mu \mathrm{m}) / 0 \mathrm{~nm}(\mu \mathrm{m})$. Conclusions are not effected by this change. 